\title{
Effect of Herbal Water, Ozonated Water, Water, and Chlorhexidine Mouthrinses on Oral Health Status of Children: A Randomized Controlled Trial
}

\author{
Jijo Mon ${ }^{1}$, Sharath Asokan², Pollachi RG Priya ${ }^{3}$, Thoppe DY Kumar ${ }^{4}$, Mythili G Balasubramaniam ${ }^{5}$
}

\begin{abstract}
Aim: To evaluate the antibacterial effect of herbal water, ozonated water, and chlorhexidine mouthrinses on salivary Streptococcus mutans level and to assess their effectiveness of these mouthrinses on the oral health status of children.

Materials and methods: A parallel multiarm randomized controlled trial was conducted in 100 children aged 10-12 years. Debris index-simplified (DI-S), calculus index-simplified (CI-S), oral hygiene index-simplified (OHI-S) scores, and Streptococcus mutans counts were recorded at baseline $\left(T_{1}\right)$. They were randomly divided into four equal groups $(n=25)$ : HW, herbal water; OW, ozonated water; W, water; and CHX, chlorhexidine. Intervention period was 15 days and data collection was repeated after 15 days $\left(T_{2}\right)$ and 30 days $\left(T_{3}\right)$. Saliva samples were used to evaluate S. mutans count. Results were tabulated and analyzed statistically.

Results: OW had minimum DI-S score at $T_{2}$ and $T_{3}$ periods. $\mathrm{HW}$ had the minimum Cl-S score at $T_{2}$ and $T_{3}$ periods. $\mathrm{CHX}$ had the minimum S. mutans count at $T_{2}$ and $T_{3}$ periods. OW showed maximum reduction in OHI-S score at $T_{2}$ period. $\mathrm{HW}$ showed maximum reduction in OHI-S score at $T_{3}$ period.

Conclusion: Herbal water and ozone water can be used as an alternative to chlorhexidine in maintaining the oral health status.

Clinical significance: Herbal water and ozonated water can be used in children instead of chemical mouthrinses to avoid any adverse effects. Keywords: Herbal mouthrinse, Herbal water, Mouthrinses, Ozonated water, Ozone, Randomized controlled trial, Tulsi. International Journal of Clinical Pediatric Dentistry (2019): 10.5005/jp-journals-10005-1693
\end{abstract}

\section{INTRODUCTION}

Dental caries is a major oral health problem in most industrialized countries, affecting $60-90 \%$ of schoolchildren and the vast majority of adults. It has shown an increasing trend in developing countries including India. ${ }^{1}$

Research in the field of caries prevention has been focusing on the ways for reducing or totally eradicating cariogenic flora from the oral cavity. Studies have shown that caries can be prevented by regular tooth brushing and flossing. However, it is difficult to eliminate Streptococcus mutans (S. mutans) from pits, fissures, and approximal surfaces by mechanical means alone. For effective caries control, it is better to combine these strategies with the chemoprophylactic agents such as mouthrinses, toothpastes, gels, and varnishes. ${ }^{1,2}$

Mouthrinses have been popularly used as a supplementary oral hygiene aid. They have the ability to deliver therapeutic ingredients and benefits to all accessible surfaces in the mouth including interproximal surfaces. ${ }^{3}$ Among them, the most commonly used is chlorhexidine ( $\mathrm{CHX}$ ) which is known to be the most potent chemotherapeutic agent against $S$. mutans and the most effective antiplaque agent. ${ }^{4,5}$ But the long-term use of $\mathrm{CHX}$ possess few adverse effects which have restricted its usage in pediatric age group and necessitated the search for alternatives. ${ }^{6,7}$

An effective and safe alternative to $\mathrm{CHX}$ mouthwash is herbal products which have lesser side effects, cheaper, and locally available. ${ }^{2,4,5}$ Tulsi is an aromatic shrub from the basil family Lamiaceae (Tribe ocimeae) and is one of the best examples of ayurveda's holistic lifestyle approach to health. Tulsi has long been

\footnotetext{
${ }^{1-4}$ Department of Pedodontics and Preventive Dentistry, KSR Institute of Dental Science and Research, Tiruchengode, Tamil Nadu, India

${ }^{5}$ Department of Biotechnology, KS Rangasamy College of Technology,
} Tiruchengode, Tamil Nadu, India

Corresponding Author: Jijo Mon, Department of Pedodontics and Preventive Dentistry, KSR Institute of Dental Science and Research, Tiruchengode, Tamil Nadu, India, Phone: +91 9895812290, e-mail: contact_drijiz@yahoo.com

How to cite this article: Mon J, Asokan S, Priya PRG, et al. Effect of Herbal Water, Ozonated Water, Water, and Chlorhexidine Mouthrinses on Oral Health Status of Children: A Randomized Controlled Trial. Int J Clin Pediatr Dent 2019;12(6):514-519.

Source of support: Nil

Conflict of interest: None

recognized as possessing antioxidant properties, as a $\mathrm{COX}_{2}$ inhibitor and to provide protection from radiation poisoning and cataracts. Agarwal et al. reported that tulsi extract had demonstrated a significant antimicrobial potential against S. mutans. ${ }^{8}$

Ozone is a powerful nonantibiotic biocide that is effective as a gas and can be dissolved in water. ${ }^{9}$ Its antimicrobial spectrum includes a wide variety of bacteria, viruses, and fungi. Its mechanism of action is by inducing oxidation of the cell wall and cytoplasmic membranes that leads to the lysis of the microorganism. Nagayoshi et al. examined the effect of ozonated water on oral microorganisms and dental plaque in vitro and almost no microorganisms were detected after being treated with ozonated water for 10 seconds. ${ }^{3}$

() The Author(s). 2019 Open Access This article is distributed under the terms of the Creative Commons Attribution 4.0 International License (https://creativecommons. org/licenses/by-nc/4.0/), which permits unrestricted use, distribution, and non-commercial reproduction in any medium, provided you give appropriate credit to the original author(s) and the source, provide a link to the Creative Commons license, and indicate if changes were made. The Creative Commons Public Domain Dedication waiver (http://creativecommons.org/publicdomain/zero/1.0/) applies to the data made available in this article, unless otherwise stated. 
The effectiveness of ozone is currently a subject of intensive research in the treatment of oral diseases. ${ }^{9-12}$ Currently, in the literature search, there are no studies conducted using ozonated water as mouthrinse in children. To consider ozone as a potential antimicrobial agent against oral pathogens, it is important to compare its effectiveness with established agents currently used in dentistry.

Hence, the aim of this study was to evaluate the antibacterial effect of herbal water, ozonated water, and chlorhexidine on salivary Streptococcus mutans level and to compare their effect on the oral health status of children.

\section{Materials and Methods}

A parallel multiarm randomized controlled trial was conducted from the Department of Pediatric and Preventive Dentistry, KSR Institute of Dental Science and Research (KSRIDSR), Tiruchengode, Tamil Nadu. The study design and protocol was analyzed and approved by the Institutional Review Board and Institutional Ethics Committee of KSRIDSR (165/KSRIDSR/EC/2016). Permission of the Assistant Elementary Educational Officer was obtained to carry out the study. One government-aided school was randomly selected by lottery method. The purpose of the study was explained to the school authorities and their approval was obtained. A total of 206 children aged were screened, and a study population of 100 was selected based on the following inclusion and exclusion criteria.

\section{Inclusion Criteria}

- Schoolchildren aged 10-12 years

- DMFT/deft score $\leq 3$

\section{Exclusion Criteria}

- Children with systemic diseases

- Children with history of antibiotics usage in past 1 month

- Children undergoing orthodontic treatment

A written consent in native language (Tamil) was also obtained from the parents of the children who participated in the study. The study was conducted between July and August 2018.

Sample size estimation was done based on the study by Ahmed et al., with the power of test at $80 \%$ and $p$ value $<0.05$ considered significant. The sample size was determined to be 20 in each group. Anticipating an attrition rate of $25 \%, 5$ samples were added to each group.

Hundred children were randomly divided into 4 groups with 25 children in each group using table of random numbers. Sequence generation and allocation was done by two dental residents who were not involved in the study (allocation ratio 1:1:1:1). The recruited children were allocated to the following groups: $\mathrm{HW}$, herbal water; OW, ozonated water; W, water; $\mathrm{CHX}$, chlorhexidine (Flowchart 1). Primary investigator was not blinded as the mouthrinses were prepared by him. He was aware of the odor and color of the mouthrinses prepared. The study population and the secondary investigators (lab technicians) who did the microbiological assessment and the statistician were blinded.

\section{In vitro Study}

Dosage optimization of herbal water against S. mutans (MTCC890) was done using well-diffusion method in Muller Hilton agar medium for intervention purpose. Screening of antimicrobial efficacy of herbal water, ozonated water, water, and chlorhexidine was determined against $S$. mutans before the conduction of intervention. Triplicates were maintained for all the three samples.

\section{In vivo Study}

\section{Measurement of Oral Health Status}

Debris and calculus scores were recorded using oral hygiene index-simplified (OHI-S) as described by John C. Greene and Jack R. Vermillion (1964) by the blinded secondary investigator. Oral prophylaxis was performed for all children, 5 days prior to the intervention. Children were instructed to carry on with their routine oral hygiene practices.

\section{Salivary Streptococcus mutans Colony Count}

All children were instructed not to eat or drink 30 minutes prior to the saliva sample collection. Unstimulated salivary samples were collected at mid-morning using sterile uricups by the primary investigator. S. mutans count was evaluated using spread plate method in brain heart infusion agar (BHI). One milliliter of the diluted saliva was plated on the agar media and the plates were inverted and incubated at $37^{\circ} \mathrm{C}$ for $48-72$ hours. The colonies were identified by colony morphological characteristics and confirmed using Gram staining (minute spherical, translucent, and pinpoint colonies that are Gram positive cocci arranged in short chains or pairs). All the counts were established for $10^{5}$ dilution and were converted to $\mathrm{CFU} / \mathrm{mL}$.

$\mathrm{CFU} / \mathrm{mL}=\frac{\text { Colonies in one quadrant of the plate } \times 2 \times \text { dilution factor }\left(10^{5}\right)}{\text { Volume of the sample }(0.1 \mathrm{~mL})}$

\section{Preparation of Mouthrinses}

Herbal water was freshly prepared everyday by adding 10 drops of Deltas Pancha tulasi drops [Delta Pharma, Mumbai, India; composition-Ocimum sanctum (60\%), Ocimum gratissimum (5\%), Ocimum canum (5\%), Ocimum basilicum (5\%), Ocimum citriodorum $(5 \%)]$ mixed in $10 \mathrm{~mL}$ of water and were given to the children in a container.

Ozonated water was freshly prepared each day by ozonation of water for 1 minute by using ozone generator (Ozone Engineers, Coimbatore). Two hundred and five liters of normal water was placed in the system with a glass tube coupled to the ozone generator. Next, triatomic form of oxygen $\left(\mathrm{O}_{3}\right)$ was bubbled through the water for 1 minute, thereby producing $\mathrm{O}_{3}$ at a concentration of $2.4 \mathrm{mg} / \mathrm{L}$ per minute ( $>2 \mathrm{ppm}$ ). From that, $10 \mathrm{~mL}$ were given to each child in a container immediately.

Five milliliters of $0.12 \% \mathrm{CHX}$ mouthwash (Chlorhex ICPA health products Ltd, India) was diluted in $5 \mathrm{~mL}$ of water every day and was given to the children in a container.

Ten milliliters of normal water was given every day to the children in a container.

All children were asked to rinse each day with the respective mouthrinses for 1 minute continuously in the morning for 15 days during school hours under the presence of the primary investigator. They were asked to refrain from eating 2 hours prior to the start of rinsing. OHI-S was taken and salivary samples were collected at 3 time periods for the determination of $S$. mutans count-at baseline $\left(T_{1}\right)$, after 15 days $\left(T_{2}\right)$, and after 30 days $\left(T_{3}\right)$. Duration of the study was 1 month. 
Flowchart 1: Methodology

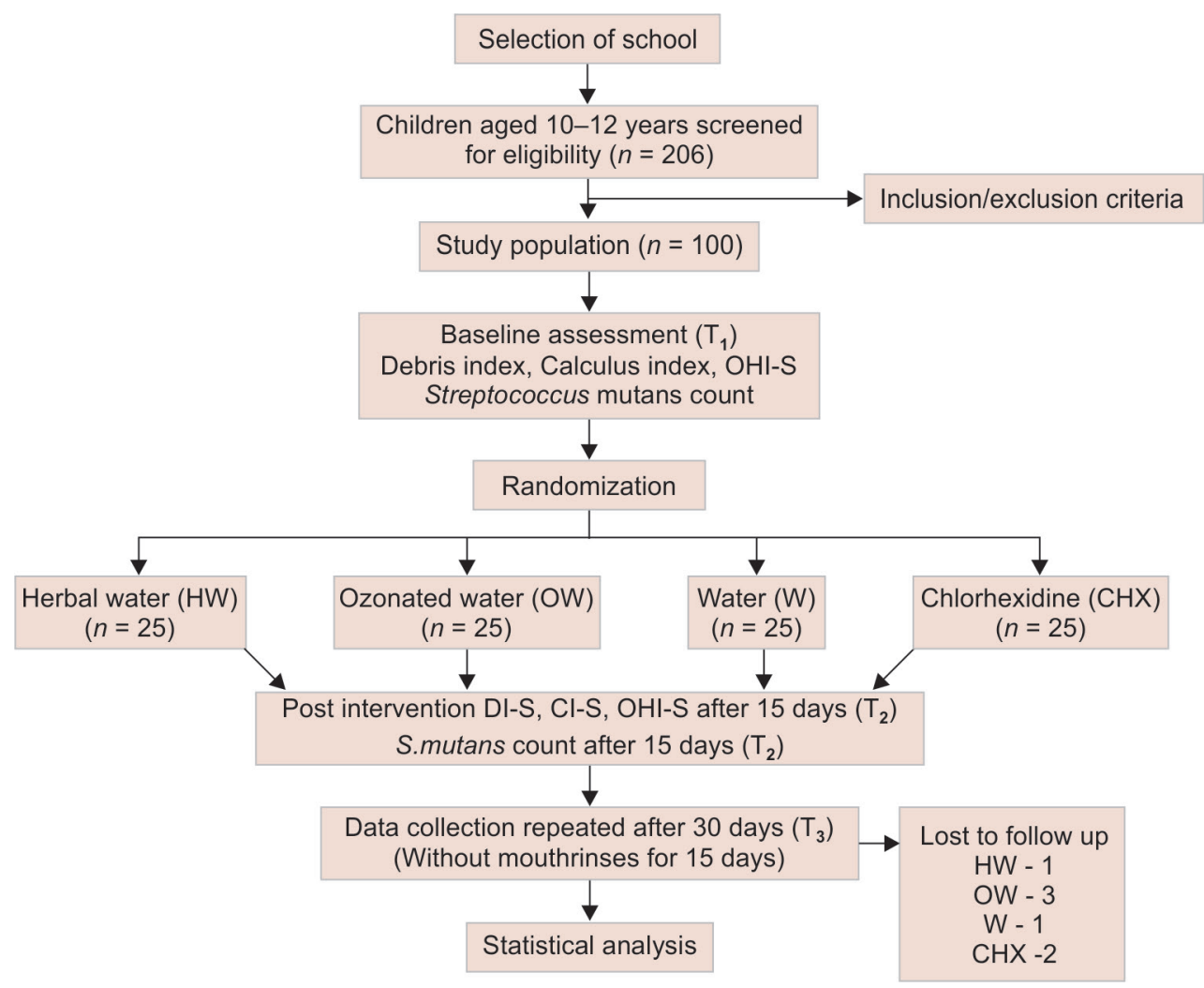

\section{Statistical Analysis}

The statistical analysis was done using IBM SPSS Statistics for Windows, Version 22.0. Armonk, NY: IBM Corp. The statistical significance was set at $p \leq 0.05$. Intragroup comparison was done using Friedman test followed by post hoc analysis using Wilcoxon signed rank test. Intergroup comparison was done by one-way ANOVA (Kruskall Wallis) test followed by post hoc analysis using Mann-Whitney $U$ test.

\section{Results}

Table 1 shows zone of inhibition in the four groups against $S$. mutans. HW, OW, and CHX groups showed zone of inhibition. HW showed the maximum zone of inhibition among the groups studied.

Table 2 shows the intragroup comparison of all variables at each time intervals in all groups. There was a significant reduction in DI-S score between $T_{1}$ and $T_{2}$ intervals and between $T_{1}$ and $T_{3}$ intervals in all the four groups. Maximum reduction in DI-S scores for all groups was seen between $T_{1}$ and $T_{2}$ intervals. HW showed a significant reduction in $\mathrm{Cl}-\mathrm{S}$ score between $T_{1}$ and $T_{2}$ intervals. There

Table 1: Zone of inhibition against S. mutans

\begin{tabular}{ll}
\hline Groups & $\begin{array}{l}\text { Zone of inhibition }(\mathrm{mm}) \\
\text { mean } \pm S D\end{array}$ \\
\hline HW & $30.33 \pm 0.88$ \\
OW & $16 \pm 0.58$ \\
W & No zone observed \\
CHX & $28.33 \pm 0.33$ \\
\hline
\end{tabular}

was a significant increase in $\mathrm{Cl}-\mathrm{S}$ score between $T_{1}$ and $T_{3}$ intervals and $T_{2}$ and $T_{3}$ intervals in $\mathrm{OW}, \mathrm{CHX}$, and $\mathrm{W}$. There was a significant reduction in OHI-S score between $T_{1}$ and $T_{2}$ intervals and $T_{1}$ and $T_{3}$ intervals in HW, OW, and CHX. There was a significant increase in $\mathrm{OHI}-\mathrm{S}$ score between $T_{2}$ and $T_{3}$ intervals in $\mathrm{OW}$ and $\mathrm{CHX}$. Maximum reduction in $\mathrm{OHI}-\mathrm{S}$ score in $\mathrm{HW}, \mathrm{OW}$, and $\mathrm{CHX}$ was seen between $T_{1}$ and $T_{2}$ intervals. There was a significant reduction in S. mutans count in $\mathrm{HW}, \mathrm{OW}$, and $\mathrm{CHX}$ between $T_{1}$ and $T_{2}$ intervals, $T_{1}$ and $T_{3}$ intervals, and $T_{2}$ and $T_{3}$ intervals, respectively. $\mathrm{HW}, \mathrm{OW}$, and $\mathrm{CHX}$ showed maximum reduction in $S$. mutans count between $T_{1}$ and $T_{3}$ intervals.

Table 3 shows intergroup comparison of all variables at different time intervals. There was no significant difference in DI-S score between the groups at $T_{1}$ period. A significant difference was seen in all the groups at $T_{2}$ and $T_{3}$ periods. At $T_{2}$ and $T_{3}$ periods, there was a significant difference between $\mathrm{HW}$ and $\mathrm{W}, \mathrm{OW}$ and $\mathrm{W}$, and $\mathrm{W}$ and $\mathrm{CHX}$. OW had minimum DI-S score at $T_{2}$ and $T_{3}$ periods. There was no significant difference between the groups in $\mathrm{Cl}-\mathrm{S}$ score at $T_{1}$ period. A significant difference was seen at $T_{2}$ and $T_{3}$ periods. At $T_{2}$ period, there was a significant difference between $\mathrm{HW}$ and $\mathrm{W}$, OW and $W$, and $W$ and $C H X$. At $T_{3}$ period, there was a significant difference between $\mathrm{HW}$ and $\mathrm{W}, \mathrm{H}$ and $\mathrm{CHX}$, OW and $\mathrm{W}$, and $\mathrm{W}$ and $\mathrm{CHX}$. HW had the minimum $\mathrm{Cl}-\mathrm{S}$ score at $T_{2}$ and $T_{3}$ periods. There was no significant difference in $\mathrm{OHI}-\mathrm{S}$ between the groups at $T_{1}$ period. At $T_{2}$ and $T_{3}$ periods, there was a significant difference seen in $\mathrm{OHI}-\mathrm{S}$ score. At $T_{2}$ and $T_{3}$ periods, there was a significant difference between HW and W, OW and W, and W and CHX. OW followed by $\mathrm{CHX}$ showed maximum reduction in $\mathrm{OHI}-\mathrm{S}$ score at $T_{2}$ period. $\mathrm{HW}$ showed maximum reduction in $\mathrm{OHI}-\mathrm{S}$ score at $T_{3}$ period. There was 
Effect of Herbal Water, Ozonated Water, Water, and Chlorhexidine Mouthrinses on Oral Health Status of Children

Table 2: Intragroup comparison of all variables at each time intervals in all groups

\begin{tabular}{|c|c|c|c|c|c|c|c|c|}
\hline & Variables & $T_{1}$ mean $\pm S D$ & $T_{3}$ mean $\pm S D$ & $T_{2}$ mean $\pm S D$ & $p$ value ${ }^{*}$ & $T_{1}$ vs $T_{2}^{* *}$ & $T_{1}$ vs $T_{3}^{* *}$ & $T_{2} v s T_{3}^{* *}$ \\
\hline \multirow[t]{4}{*}{$\mathrm{H}$} & DI-S & $1.73 \pm 0.48$ & $0.80 \pm 0.37$ & $0.91 \pm 0.31$ & $<0.001$ & 0.001 & 0.001 & \\
\hline & $\mathrm{Cl}-\mathrm{S}$ & $0.20 \pm 0.31$ & $0.09 \pm 0.17$ & $0.11 \pm 0.18$ & 0.04 & 0.01 & & \\
\hline & $\mathrm{OHI}-\mathrm{S}$ & $1.93 \pm 0.70$ & $0.89 \pm 0.43$ & $1.02 \pm 0.36$ & 0.001 & 0.001 & 0.001 & \\
\hline & S. mutans & $19.20 \pm 30.5$ & $4.87 \pm 3.5$ & $2.87 \pm 1.56$ & $<0.001$ & $<0.001$ & $<0.001$ & 0.01 \\
\hline \multirow[t]{4}{*}{ OW } & DI-S & $1.86 \pm 0.39$ & $0.73 \pm 0.40$ & $0.86 \pm 0.28$ & $<0.001$ & 0.001 & 0.001 & \\
\hline & $\mathrm{Cl}-\mathrm{S}$ & $0.11 \pm 0.19$ & $0.10 \pm 0.17$ & $0.24 \pm 0.24$ & 0.002 & & 0.02 & 0.005 \\
\hline & $\mathrm{OHI}-\mathrm{S}$ & $1.97 \pm 0.43$ & $0.83 \pm 0.44$ & $1.11 \pm 0.43$ & 0.001 & 0.001 & 0.001 & 0.031 \\
\hline & S. mutans & $12.76 \pm 9.7$ & $6.14 \pm 4.04$ & $2.23 \pm 0.76$ & $<0.001$ & 0.003 & $<0.001$ & $<0.001$ \\
\hline \multirow[t]{4}{*}{ W } & DI-S & $1.74 \pm 0.62$ & $1.25 \pm 0.39$ & $1.27 \pm 0.39$ & $<0.001$ & 0.001 & 0.001 & \\
\hline & $\mathrm{Cl}-\mathrm{S}$ & $0.14 \pm 0.21$ & $0.29 \pm 0.33$ & $0.50 \pm 0.32$ & 0.005 & & 0.001 & 0.001 \\
\hline & $\mathrm{OHI}-\mathrm{S}$ & $1.87 \pm 0.76$ & $1.54 \pm 0.61$ & $1.77 \pm 0.63$ & 0.08 & & & \\
\hline & S. mutans & $15.41 \pm 11.89$ & $17.37 \pm 17.25$ & $15.33 \pm 3.0$ & 0.42 & & & \\
\hline \multirow[t]{4}{*}{$\mathrm{CHX}$} & DI-S & $1.69 \pm 0.39$ & $0.76 \pm 0.37$ & $0.87 \pm 0.23$ & $<0.001$ & 0.001 & 0.001 & \\
\hline & $\mathrm{Cl}-\mathrm{S}$ & $0.095 \pm 0.50$ & $0.095 \pm 0.49$ & $0.25 \pm 0.39$ & $<0.001$ & & 0.004 & 0.001 \\
\hline & $\mathrm{OHI}-\mathrm{S}$ & $1.80 \pm 0.50$ & $0.83 \pm 0.49$ & $1.125 \pm 0.39$ & 0.001 & 0.001 & 0.001 & 0.003 \\
\hline & S. mutans & $14.13 \pm 12.8$ & $3.043 \pm 1.9$ & $1.86 \pm 1.74$ & $<0.001$ & $<0.001$ & $<0.001$ & 0.01 \\
\hline
\end{tabular}

*Friedman test; ** post hoc Wilcoxon signed rank test

no significant difference in $S$. mutans count between the groups at $T_{1}$ period. A significant difference was seen at $T_{2}$ and $T_{3}$ periods. At $T_{2}$ and $T_{3}$ periods, there was a significant difference in $S$. mutans count between HW and W, HW and $\mathrm{CHX}$, OW and W, and W and $\mathrm{CHX}$. CHX had the minimum S. mutans count at $T_{2}$ and $T_{3}$ periods.

\section{Discussion}

This study was conducted to evaluate and compare the antibacterial effect of herbal water, ozonated water, and CHX on salivary S. mutans level in children. Age group of 10-12 years were selected because they belong to the concrete operational stage of Jean Piaget's cognitive theory. Hence, they accept the rules and they follow the instructions given to them. ${ }^{13}$ This age group of children can easily rinse the mouthwash without swallowing it and hence side effects of mouthrinses can be avoided. ${ }^{6,14}$ Oral prophylaxis was carried out for all the study subjects to maintain homogeneity in baseline data between the groups. ${ }^{5}$

\section{In vitro Trials}

In our study, we used Deltas Pancha tulasi drops which is in liquid form and is chemical and alcohol free. According to the manufacturer, it can be used as a natural water purifier. It has antibacterial, antimicrobial, anti-infective, immune modulator, powerful antioxidant activity, and is also used as natural adjuvant in the management of cough and cold. Its antimicrobial activity was demonstrated by Agarwal et al. who obtained a zone of inhibition of $22 \mathrm{~mm}$ with $4 \%$ tulsi extract. ${ }^{15}$ In our study, we found herbal water with a mean zone of inhibition of $30 \pm 0.88 \mathrm{~mm}$, which was slightly better than CHX with a zone of inhibition of $28.3 \pm 0.33 \mathrm{~mm}$. Zone of inhibition against $S$. mutans was least in ozonated water which was $16 \pm 0.58 \mathrm{~mm}$ when compared to herbal water and $\mathrm{CHX}$. This might be due to the fact that ozonated water has a short halflife as ozone lasts at full strength in water for as little as 20 minutes. This was in contrast with an in vitro study by Anand et al. where ozonated water showed complete inhibition of $S$. mutans and E. feacalis. ${ }^{16}$ Concentration of $\mathrm{O}_{3}$ was $2.4 \mathrm{mg} / \mathrm{L}$ per minute ( $>2 \mathrm{ppm}$ ) similar to the study by Katti et al. ${ }^{17}$

\section{Oral Health Status}

\section{Debris Index-simplified Score}

All the groups including water group showed a reduction of DI-S score after 15 days. These values slightly increased after a follow-up of 15 days $\left(T_{3}\right)$ without using mouthrinses but was significantly lesser than the baseline scores. All groups showed maximum reduction in DI-S score during the use of mouthrinses. From this study, it was clear than even normal rinsing with water can remove debris. Ozonated water was comparatively better in reducing debris after 15 days of usage of mouthrinses and at the end of the follow-up period.

\section{Calculus Index-simplified Score}

The reduction in $\mathrm{Cl}-\mathrm{S}$ score was seen only in herbal water group, whereas there was no change in calculus status in ozonated water and $\mathrm{CHX}$ groups after using mouthrinses for 15 days. Supragingival calculus is essentially a mineralized plaque. Immature calculus formation would be more accelerated due to other factors like poor brushing, diet, or any medications, as mouthrinse is just an adjunct that can lead to early mineralization. Moreover, there is a higher tendency to calculus formation in lingual aspects of lower anterior and buccal aspects of upper posterior tooth surfaces due to the location of the submandibular and parotid ducts location. The presence of the low sucrose concentration in saliva with a high saliva film velocity promoting clearance of salivary sugar and acid from plaque, and the higher plaque $\mathrm{pH}$ associated to better access to salivary urea in these areas tends to promote base formation to plaque and calcium phosphate precipitation. ${ }^{18,19}$ This can lead to calculus formation in a faster stage. Clearly, herbal water was the only mouthrinse that was found to be better in reducing calculus when compared to others after 30 days. A probable explanation might be that herbal water was successful in reducing the immature calculus formation. After follow-up for 15 days without mouthrinses, $\mathrm{Cl}-\mathrm{S}$ score increased significantly more than the baseline value in all the groups except herbal water group. This was another conclusive finding in our study that after cessation of mouthrinses use, there was more calculus formation than when with use of mouthrinses. 


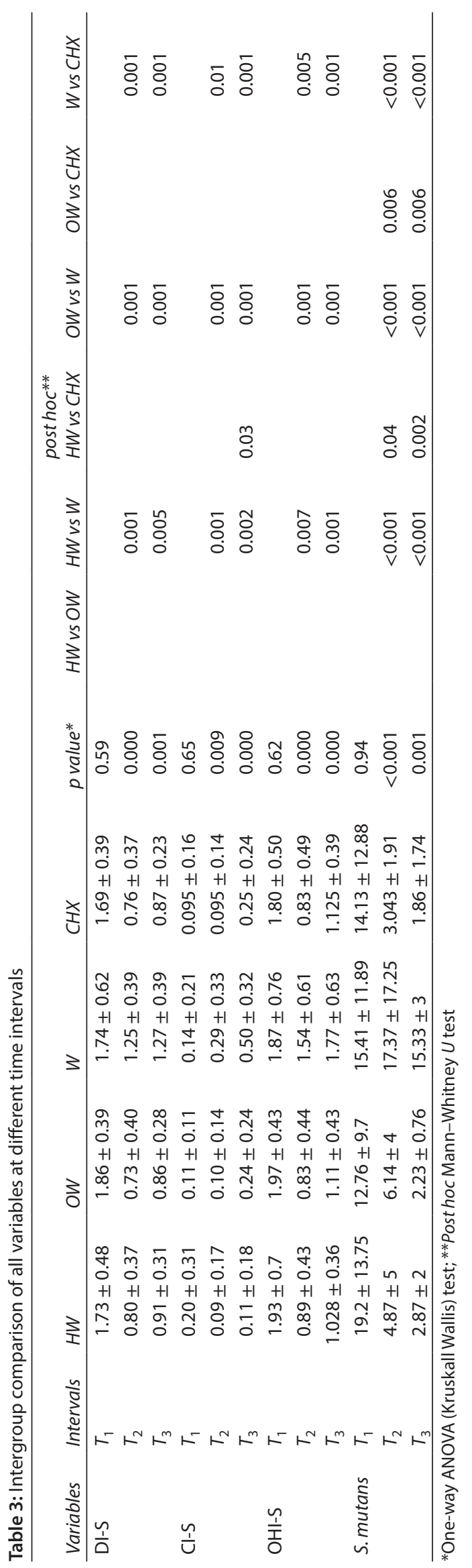

In water group, $\mathrm{Cl}-\mathrm{S}$ score increased throughout the study period in both with/without rinsing. Water rinsing might not be effective in preventing further calculus formation.

\section{Oral Hygiene Index-simplified Score}

There was a reduction in OHI-S score in herbal water, ozonated water, and $\mathrm{CHX}$ groups after 15 days. Ozonated water and $\mathrm{CHX}$ showed a significant increase in OHI-S after 15 days without mouthrinses but did not reach up to their previous baseline values. Maximum reduction of $\mathrm{OHI}-\mathrm{S}$ score was during the use of mouthrinse. Though water had a slight decrease in OHI-S score, it was not clinically significant. Ozonated water was more effective in reducing overall $\mathrm{OHI}-\mathrm{S}$ score followed by $\mathrm{CHX}$ after 15 days of use of mouthrinses. But, by the end of the study, herbal water was found to be effective in having the least OHI-S score which might be due to the Hawthorne effect. This was in contrast with the study conducted by Ahmed et al., where he found $\mathrm{CHX}$ was more effective than tulsi extract (herbal) mouthrinse in the age group of 15 years in reducing $\mathrm{OHI}-\mathrm{S}$ score. But their study had a short duration of 2 weeks. ${ }^{6}$ Our study period was 30 days which involved a follow-up of 15 days without mouthrinses.

\section{Salivary S. mutans}

There was a reduction in S. mutans count in all the groups except water after usage of mouthrinses for 15 days. Interestingly, these counts further decreased in all the groups except water at the end of 30 days. $\mathrm{CHX}$ was found to be more effective in reducing S. mutans count followed by herbal water and ozonated water. CHX indirectly affects the enzymatic function of dehydrogenase and adenosine triphosphatase present in the cell wall of bacteria resulting in the disruption of cell membrane. ${ }^{6,20}$ Various studies in the literature have showed the superiority of chlorhexidine when compared with other ingredients in reducing S. mutans. ${ }^{6}$ Effectiveness of herbal water may be attributed to single active component (tulsi) or combination of other herbal ingredient traces acting against S. mutans. Moreover, the dosage optimization of herbal water was obtained in vitro from its zone of inhibition against $S$. mutans to know its antimicrobial activity. Ozonated water had significantly influenced the $S$. mutans population under in vivo condition rather than in vitro study against $S$. mutans. Ozone when dissociates into oxygen, creates an oxygen-rich environment, thus disturbing the normal ecosystem of the plaque. The enzymatic control system of the cell is blocked as ozone inhibits glycoproteins, glycolipids, and other amino acids; the outcome of which is the functional cessation and death of the microorganism. ${ }^{21}$ Anumula et al. compared the antibacterial efficacy of freshly prepared ozonated water with $\mathrm{CHX}$ against $S$. mutans for 14 days and concluded that ozonated water showed significant reduction of mutan Streptococcus count and could be used as an alternative to $\mathrm{CHX} .{ }^{22}$ Though $\mathrm{CHX}$ was found to be superior to herbal water and ozonated water, one cannot rule out that it has shortcomings such as mucosal desquamation, impaired wound healing, and fibroblast attachment to the tooth surfaces. ${ }^{12,23}$

The literature search showed no ill effects of tulsi on human beings, so one can confidently recommend the use of tulsi as a mouthrinse, especially for rural population which has an easy access to tulsi and it is also highly cost-effective. One disadvantage using tulsi we observed in our study was that few participants initially had a slight unacceptance toward the bitter taste of tulsi. Tulsi tastes hot and bitter but is said to penetrate the deep tissue and dry tissue secretions. ${ }^{8}$ Ozonated water is also cost-effective as for purifying water with a lower power, ozone generators at cheaper rates are 
also available in the market. In our study, the participants who used ozonated water were more willingful to use it as its appearance did not differ much from the normal water other than in slight change in odor and taste. The only shortcoming is that $\mathrm{O}_{3}$ molecule is unstable and ozonated water should be prepared immediately before use. Its oxidizing property gradually decreases with time. ${ }^{22}$

\section{Limitations}

There is a need to study the long-term effects of the mouthrinses on oral health with a larger sample. The role of these mouthrinses needs to be assessed with emphasis on individuals with poor oral hygiene with different caries status, to get better picture of the antibacterial properties of these mouthrinses. Further studies are required to find the optimum ozonation time and concentration as required for mouthrinse.

\section{CONCLUSION}

- Ozonated water was more effective in reducing debris followed by herbal water and $\mathrm{CHX}$.

- Herbal water was the only mouthrinse that was found to be effective in reducing calculus.

- Chlorhexidine was found to be the most effective in reducing S. mutans count when compared with other mouthrinses studied.

- From this study, it is clear that herbal water and ozonated water can be used as an alternative to $\mathrm{CHX}$.

\section{Clinical Significance}

Herbal water and ozonated water can be used in children instead of chemical mouthrinses to avoid any adverse effects. Moreover, they are safer and cost-effective.

\section{Acknowledgment}

ICPA Health Products LTD, India.

\section{References}

1. Bagramian RA, Garcia-Godoy F, Volpe AR. The global increase in dental caries. A pending public health crisis. Am J Dent 2009;22(1): 3-8.

2. Kaur RK, Singh MP, Chopra R, et al. To evaluate the efficacy of three commercially available herbal mouthwashes in treatment of chronic gingivitis: a comparative clinical study. Int J Dent Med Res 2014;1(4):42-46.

3. Nagayoshi M, Fukuizumi T, Kitamura C, et al. Efficacy of ozone on survival and permeability of oral microorganisms. Oral Microbiol Immunol 2004;19(4):240-246. DOI: 10.1111/j.1399-302X.2004. 00146.x.

4. Deshmukh MA, Dodamani AS, Karibasappa G, et al. Comparative evaluation of the efficacy of probiotic, herbal and chlorhexidine mouthwash on gingival health: a randomized clinical trial. J Clin Diagn Res 2017;11(3):ZC13-ZC16. DOI: 10.7860/JCDR/2017/23891. 9462.

5. Nagappan N, John J. Antimicrobial efficacy of herbal and CHX mouth rinse -a systematic review. J Dent Med Sci 2012;2(4):5-10.
6. Ahmed SI, Sekhara Reddy VC, Sudhir KM, et al. Effect of tulsi extract and honey mouthrinses on salivary Streptococcus mutans count in comparison with $0.2 \%$ of chlorhexidine: a randomized controlled trial. J Indian Assoc Public Health Dent 2017;15:306-311. DOI: 10.4103/ jiaphd.jiaphd_55_17.

7. Mehta S, Pesapathy S, Joseph M, et al. Comparative evaluation of a herbal mouthwash (Freshol) with chlorhexidine on plaque accumulation, gingival inflammation, and salivary Streptococcus mutans growth. J Int Soc Prev Communit Dent 2013;3(1):25-28. DOI: 10.4103/2231-0762.115717.

8. Agarwal P, Nagesh L. Comparative evaluation of efficacy of $0.2 \%$ chlorhexidine, listerine and tulsi extract mouth rinses on salivary Streptococcus mutans count of high school children-RCT. Contemp Clin Trials 2011;32(6):802-808. DOI: 10.1016/j.cct.2011.06.007.

9. Hems RS, Gulabivala $\mathrm{K}, \mathrm{Ng} \mathrm{YL}$, et al. An in vitro evaluation of the ability of ozone to kill a strain of Enterococcus faecalis. Int Endod J 2005;38(1):22-29. DOI: 10.1111/j.1365-2591.2004.00891.x.

10. Arita M, Nagayoshi M, Fukuizumi T, et al. Microbicidal efficacy of ozonated water against Candida albicans adhering to acrylic denture plates. Oral Microbiol Immunol 2005;20(4):206-210. DOI: 10.1111/j.1399-302X.2005.00213.x.

11. Baysan A, Lynch E. The use of ozone in dentistry and medicine. Part 2. Ozone and root caries. Prim Dent Care 2006;13(1):37-41. DOI: $10.1308 / 135576106775193897$.

12. Bezrukova IV, Petrukhina NB, Voinov PA. Experience in medical ozone use for root canal treatment. Stomatologiia (Mosk) 2005;84(6):20-22.

13. Piaget J. Piaget and his school. Piaget's theory. Springer Berlin Heidelberg; 1976. pp. 11-23.

14. WHO Oral Health Surveys - Basic Methods, 4th ed., New Delhi: A. I. T. B. S. Publishers and Distributors; 1997.

15. Agarwal $P$, Nagesh $L$, Murlikrishnan. Evaluation of the antimicrobial activity of various concentrations of Tulsi (Ocimum sanctum) extract against Streptococcus mutans: an in vitro study. Indian J Dent Res 2010;21(3):357-359. DOI: 10.4103/0970-9290.70800.

16. Anand SK, Ebenezar AV, Anand N, et al. A comparative analysis of antimicrobial property of wine and ozone with calcium hydroxide and chlorhexidine. J Clin Diagn Res 2015;9(6):ZC04-ZC06. DOI: 10.7860/ JCDR/2015/11355.6030.

17. Katti SS, Chava VK. Effect of ozonised water on chronic periodontitis - a clinical study. J Int Oral Health 2013;5(5):79-84.

18. Dawes $C$, MacPherson LM. The distribution of saliva and sucrose around the mouth during the use of chewing gum and the implications for the site specificity of caries and calculus deposition. J Dent Res 1993;72(5):852-857. DOI: 10.1177/00220345930720050401.

19. Löe $H$, Mandell M, Derry A, et al. The effect of mouthrinses and topical application of chlorhexidine on calculus formation in man. J Periodontal Res 1971;6(4):312-314. DOI: 10.1111/j.1600-0765.1971. tb00623.x.

20. Löe H, Schiott CR. The effect of mouthrinses and topical application of chlorhexidine on the development of dental plaque and gingivitis in man. J Periodontal Res 1970;5:79-83. DOI: 10.1111/j.1600-0765.1970. tb00696.x.

21. Celiberti P, Pazera P, Lussi A. The impact of ozone treatment on enamel physical properties. Am J Dent 2006;19:67-72.

22. Anumula L, Kumar KVS, Krishna CM, et al. Antibacterial activity of freshly prepared ozonated water and chlorhexidine on mutans streptococcus when used as an oral rinse - a randomised clinical study. J Clin Diagn Res 2017;11(7):ZC05-ZC08.

23. Cline NV, Layman DL. The effects of chlorhexidine on the attachment and growth of cultured human periodontal cells. J Periodontol 1992;63(7):598-602. DOI: 10.1902/jop.1992.63.7.598. 